Vol. 1 No. 1, Feb 2021, hlm. $1-8$

DOI: https://doi.org/10.33330/.v1i1.1004

Available online at https://jurnal.stmikroyal.ac.id/index.php/jutsi

\title{
SISTEM MONITORING JARAK JAUH PADA SUHU KOLAM IKAN NILA BANGKOK MEMANFAATKAN INTERNET OF THINGS (IOT) BERBASIS NODEMCUESP8266
}

\author{
Suriana $^{1}$, Adi Prijuna Lubis ${ }^{2 *}$, Elly Rahayu ${ }^{3}$ \\ ${ }^{1}$ Mahasiswa Prodi Sistem Komputer, STMIK Royal \\ ${ }^{2}$ Prodi Sistem Komputer, STMIK Royal \\ ${ }^{3}$ Prodi Sistem Informasi, STMIK Royal \\ *email:pri7n4@gmail.com
}

\begin{abstract}
In general, many fish farmers currently cultivate Bangkok tilapia, but one of the problems faced by tilapia farmers is the fluctuation of fish pond water temperature in tarpaulin ponds, where fish pond farmers do not know if the temperature is too cold at night, if tilapia breeders The Bangkok can monitor temperature changes remotely, and has an automation system to neutralize pool water until it becomes slightly warm by utilizing a heater. Based on the problem of temperature changes in fish ponds, resulting in the death of Bangkok tilapia fish seeds, the researchers wanted to design a distance monitoring system, so that if there was a change in temperature in the fish pond, the fish pond owner received the temperature change data and turned on the heater or turned off the heater automatically. automatic. The monitoring system can be seen from the temperature thermometer on the fish pond owner's smartphone, and data changes, if it exceeds the provisions, will be sent via a notification so that if there is a temperature change in the fish pond, a notification will be sent by the nodemcu server to the android owner's mobile phone and the temperature value read by the DS18b20 sensor will be displayed by android.
\end{abstract}

Keywords:Remote Control System, Bangkok Tilapia, Pool Water Heater, Internet of Things, Controller

\begin{abstract}
Abstrak:Pada umumnya peternak ikan saat ini banyak yang membudidayakan ikan nila bangkok namun salah satu masalah yang dihadapi peternakn ikan nila berupa turun naiknya suhu air kolam ikan pada kolam terpal, dimana peternak kolam ikan tidak tahu jika suhu terlalu dingin pada malam hari, Seandainya peternak ikan nila bangkok tersebut bisa memonitoring perubahan suhu dari jarak jauh, dan memiliki sistem otomatisasi untuk menetralisir air kolam hingga menjadi sedikit hangat dengan memanfaatkan heater (Pemanas). Berdasarkan masalah tentang perubahan suhu pada kolam ikan, sehingga mengakibatkan matinya bibit ikan nila bangkok, maka peneliti ingin merancang sistem monitoring jarak, sehingga jika terjadi perubahaan suhu pada kolam ikan, maka pemilik kolam ikan menerima data perubahan suhu tersebut dan menyalakan pemanas atau mematikan pemanas secara otomatis. Sistem monitoring bisa dilihat dari thermometer suhu yang ada diheandphone pemilik kolam ikan, dan data perubahan jika melebihi ketentuan akan dikirimkan melalui notif sehingga jika terjadi perubahan suhu pada kolam ikan, maka notifikasi akan dikirimkan oleh server nodemcu ke hendphone pemilik android serta nilai suhu yang dibaca oleh sensorDS18b20 akan ditampilkan oleh android.
\end{abstract}

Kata kunci:System Kendali Jarak Jauh, Ikan Nila Bangkok, Pemanas AirKolam, Internet of Things, Controller 
Vol. 1 No. 1, Feb 2021, hlm. 1 -8

DOI: https://doi.org/10.33330/.v1i1.1004

Available online at https://jurnal.stmikroyal.ac.id/index.php/jutsi

\section{PENDAHULUAN}

Ikan Nila (Oreochromis niloticus) merupakan ikan air tawar, ikan yang dapat hidup di daerah dataran rendah yang bersifat (eurihaline) hidup di perairan bersalinitas tinggi. Ikan nila juga termasuk ikan yang dikenal ikan komsumsi untuk masyarakat dan tingkat pemintaannya sangatlah tinggi sehingga konsumen juga mudah didapatkan[1].

Nila Bangkok remasuk ikan yang dapat dibudidayakan banyak peternak ikan memilih jenis ikan nila bangkok sebagai sumber pendapatan untuk kehidupannya sehari hari. Ikan nila juga banyak dicari untuk komsumsi dimasyarakat dengan daging ikan yang sangat tebal dan padat dan juga ikan tidak memiliki banyak duri sehingga yang konsumsi lebih gampang untuk memakannya, ikan nila bangkok yang berwarna merah jingga dagingnya juga serasa seperti ikan kakap merah. Ikan nila bangkok juga harga jual dipasaran sangatlah tinggi jika dibandingkan dengan ikan nila lainnya. Danil sirait merupakan salah satu pengusaha ikan nila yang berada diwilayah kampung tanjungleidong, dimana unit usaha yang digelutinya saat ini memiliki 5 kolam nila terpal dan 2 kolam nila permanen (Kolam semen). Tiap kolam memiliki ukuran nila bangkok yang berbeda beda dan jumlah yang berbeda beda.

Kendala atau masalah yang umum dihadapi pada saat membudidayakan ikan nila bangkok saat ini adalah kondisi suhu air kolam nila yang tidak menentu, sehingga terkadang bibit ikan nila bangkok banyak mati dikarenakan perubahan suhu air yang tidak menentu pada malam dan siang hari. Untuk mengantisipasi perubahan suhu kolam yang berubah ubah, selama ini peternak ikan pada kolam tersebut menggunakan alat berupa thermometer untuk membaca suhu kolam ikan, sehingga jika suhu kolam terlalu dingin biasanya petani menggunakan terpal semen untuk melapisi kolam terpal dari luar, dan jika suhu terlalu panas kolam dimasukan tumbuhan air berupa enceng gondok. Suhu yang dijadikan patokan untuk kolam terpal pada nila bangkok, berkisar antara $28^{\circ} \mathrm{C}-30^{\circ} \mathrm{C}$. Salah satu masalah yang dihadapi berupa turun naiknya suhu air kolam ikan pada kolam terpal, dimana peternak kolam ikan tidak tahu jika suhu terlalu dingin pada malam hari, sehingga terkadang lupa untuk memasang jerami, atau terkadang pemasangan jerami pada malam hari terkadang membuat ikan kepanasan, dikarenakan suhu pada malam hari terkadang agak panas.

Jika peternak ikan nila bangkok tersebut bisa memonitoring perubahan suhu dari jarak jauh, dan memiliki sistem otomatisasi untuk memanaskan air kolam dengan memanfaatkan heater (Pemanas) maka akan meminimalisir kematian bibit ikan nila bangkok mati karena perubahan suhu. Sistem monitoring jarak jauh dapat memanfaatkan jaringan internet of things (IOT) pada smartphone.

Internet of things ( IOT) merupakan perangkat atau alat hardware (Raspberry Pi) dapat terkoneksi jaringan internet dalam tujuan memperluas koneksi jaringan dengan perangakat keras secarah menyeluruh [2]. Internet of things (IoT) digunakan sebagai mengendalikan peralatan yang bisa dioperasikan melalui jaringan dan dapat diterapkan melalui mobile dari jarak jauh sehingga dapat mempermuadah untuk memantau perangkat elektronik tersebut[3].Komponen elektronik sebagai pendukung dan dapat bekerja sesuai dengan kegunaannya. Rangakian elektronik dapat berfungsi dengan baik sesuai dengan masing masing desain rangakian yang diinginkan. Dapat mengatur tegangan arus yang masuk, memperkuat sinyal arus juga masi banyak kegunaan fungsi lainnya [4], [5]. 
Vol. 1 No. 1, Feb 2021, hlm. 1 - 8

DOI: https://doi.org/10.33330/.v1i1.1004

Available online at https://jurnal.stmikroyal.ac.id/index.php/jutsi

Perkembangan sistem monitoring saat ini sudah semakin pesat dimulai dari perkembangan informasi dari monitor berupa monitor gambar atau tulisan, pengiriman informasi melalui pesan singkat sampai dengan penampilan informasi ditampilan android atau perangkat interface yang menggunakan system internet of things (IOT). Perkembangan IOT juga disupport dengan perkembangan dari android, sehingga IOT bisa diaplikasikan kedalam android, dengan menjadikan android sebagai server utama pembaca sinyal wifi atau internet.

Berdasarkan masalah tentang perubahan suhu pada kolam ikan, sehingga mengakibatkan matinya bibit ikan nila bangkok, maka peneliti ingin merancang system monitoring jarak jauh, sehingga jika terjadi perubahaan suhu pada kolam ikan, maka pemilik kolam ikan menerima data perubahan suhu tersebut dan menyalakan pemanas atau mematikan pemanas secara otomatis

\section{METODE}

Dalam penelitian ini mengunakan metode kualitatif yang merupakan metode pendekatan, penelitian yang mewakili paham naturalistik (fenomenologis). Peneliti melakukan wawancara langsung terhadap objek untuk pengalian data. Serta melakukan obserpasi langsung bagaimana penggalian data memberikan makna arti terhadap penomena terkait.

Pengumpulan data dilakukan diperternakan ikan di tanjung leidong, pengamatan (Observation), Kolam ikan terdiri dari 4 kolam jenis kolam intensif yang terbuat dari terpal, tiap kolam memiliki ukuran kolam yang berbeda beda, dan jenis ikan yang sama, pembacaan suhu air kolam tidak pernah dilakukan, penjagaan suhu air kolam dengan menggunakan tumbuhan air (enceng gondok) dan menggunakan jerami atau goni bekas semen untuk menjaga suhu tetap hangat.terkadang ditiap pagi ada beberapa ekor bibit ikan nila Bangkok mati dikarenakan air kolam yang terasa dingin.

Berdasarkan keadaan dipeternakan ikan di tanjung leidong, maka peneliti ingin merancang sebuah monitoring jarak jauh pada suhu kolam dengan memanfaatkan jaringan internet of things (IOT) dimana tampilan suhu dan sistem pengaktif pemanas air kolam akan dipantau dan dikendalikan melalui android dengan memanfaatkan koneksi internet network. Langkah awal yang harus dilakukan membuat suatu blok diagram, dimana blog diagram adalah gambaran singkat suatu perancangan alat. Blok diagram sistem monitoring jarah jauh pada suhu kolam ikan nila bangkok memanfaatkan internet ofthing (IOT) berbasis Nodemcuesp8266.

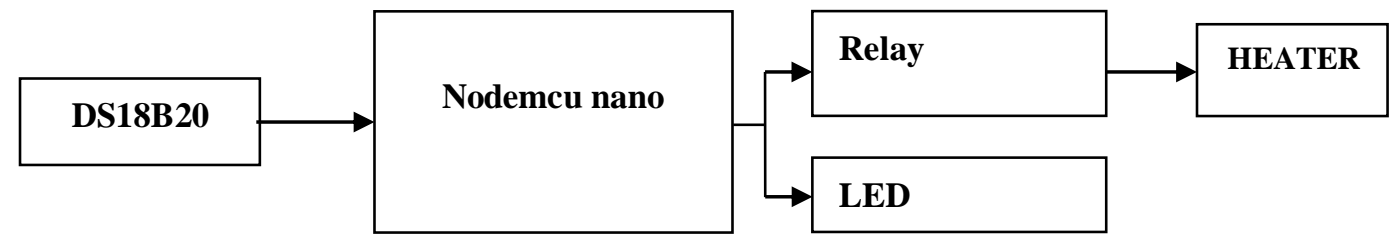

Gambar 1. Blok Diagram Sistem 
Vol. 1 No. 1, Feb 2021, hlm. 1 - 8

DOI: https://doi.org/10.33330/.v1i1.1004

Available online at https://jurnal.stmikroyal.ac.id/index.php/jutsi

Blok diagram merupakan perancangan piranti - piranti pendukung yang utama, perangkat yang dibutuhkan dapat dijelaskan diantaranya pada gambar 2 .

1

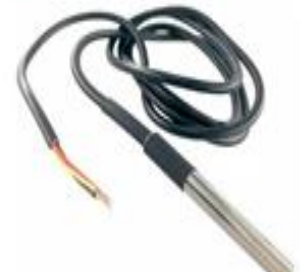

4

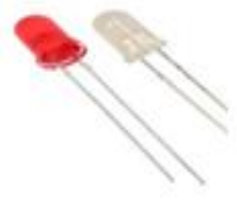

2

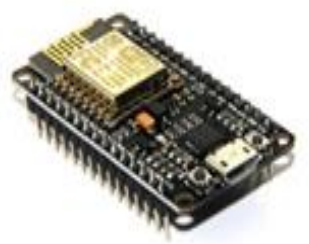

5

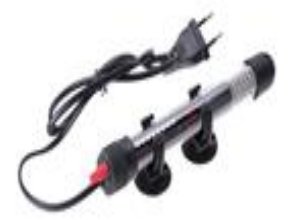

3

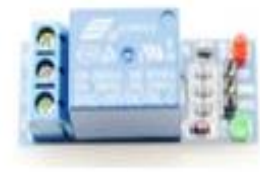

Keterangan

1. DS 18620

2. NodeMCU

3. Relay

4. Led

5. Heater

Gambar 2. Perangakat keras yang digunakan

\section{Perangkat keras (hadware)}

DS18B20 merupakan sensor suhu digital mengirim dan menerima data dari mikrokontroler. Sedangakan NodeMCU sebuah platform IoT yang bersifat open source. Terdiri dari perangkat keras berupa System OnChip (SoC) ESP8266-12 buatan Espressif System, juga firmware yang menggunakan bahasa pemrograman scripting Lua.

Relay merupakan piranti saklar (switch) elektronik yang bisa dikendalikan melalui rangkaian piranti elektronik lainya. Elektromagnetik menggerakan kontaktor yang tersusun. Energi yang dimanfaatkan sebagai sumber tegangan berupa arus listrik. sedangkan Heater digunakan untuk membuat suhu air didalam aquarium stabil, agar ikan terhindar atau meminimalisir dari serangan penyakit semisal dari jamur atau bakteri. Suhu yang stabil juga bisa menjaga mood ikan dari stress.

\section{Software Blynk}

Blynk merupakan platform sistem operasi iOS maupun Android sebagai kendali pada modul Arduino, Raspberry Pi, ESP8266 dan perangkat sejenis lainnya melalui internet. 
Vol. 1 No. 1, Feb 2021, hlm. 1 - 8

DOI: https://doi.org/10.33330/.v1i1.1004

Available online at https://jurnal.stmikroyal.ac.id/index.php/jutsi

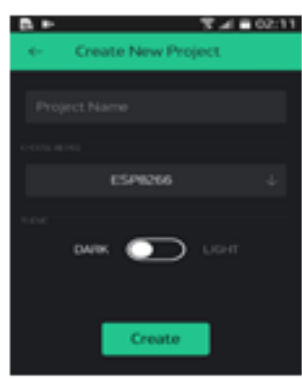

(a) Create New Project

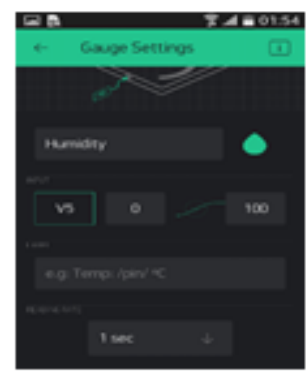

(d) Gange temperature

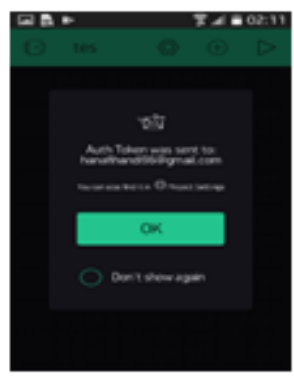

(b) Auth Token

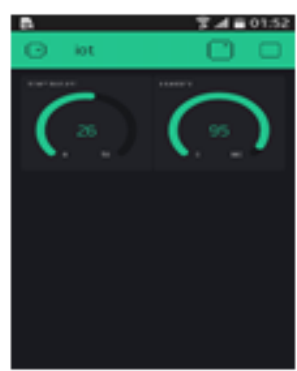

(e) Gauge temperature

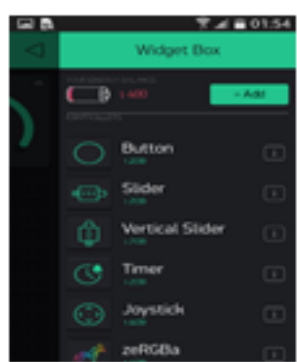

(c) Widget box

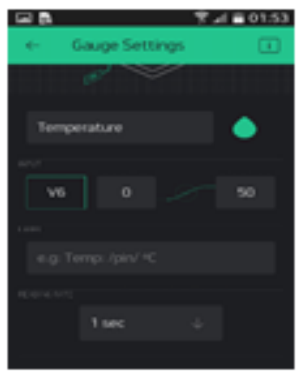

(f) Gauge humidity

Gambar 3. Tampilan pembuatan aplikasi blynk

Beberapa tahapan perancangan Blynk yaitu (a) membuat proyek baru, (b) mengirim autentiikasi Blynk token ke email untuk diterapkan pada kode program, (c)membuat gauges yang akan digunakan, (d) mengatur tampilan dari nilai temperature, (e) mengatur tampilan dari nilai humidity (f) user interface aplikasi Blynk sebagai antar muka monitor data sensor[6].

\section{HASIL DAN PEMBAHASAN}

\section{Perancangan Protype}

Dari perancangan sistem monitoring jarak jauh pada suhu kolam ikan nila bangkok memanfaatkan internet of things (IOT) berbasis Nodemcuesp8266. Sistem pengujian Relay menggunakan tegangan kerja yang ada di nodemcu, serta menggunakan tegangan dari luar. Sehingga pada saat beban akan ditambah, bisa memanfaatkan tegangan dari luar seperti menggunakan tegangan dari power supply. Perubahan Relay dilihat dari perubahan posisi NO (normalopen) Relay terbuka dan tertutup NC (normalclose), hal ini bisa terjadi karena magnet Relay diberi tegangan dan mengubah posisi magnet. 
Vol. 1 No. 1, Feb 2021, hlm. $1-8$

DOI: https://doi.org/10.33330/.v1i1.1004

Available online at https://jurnal.stmikroyal.ac.id/index.php/jutsi

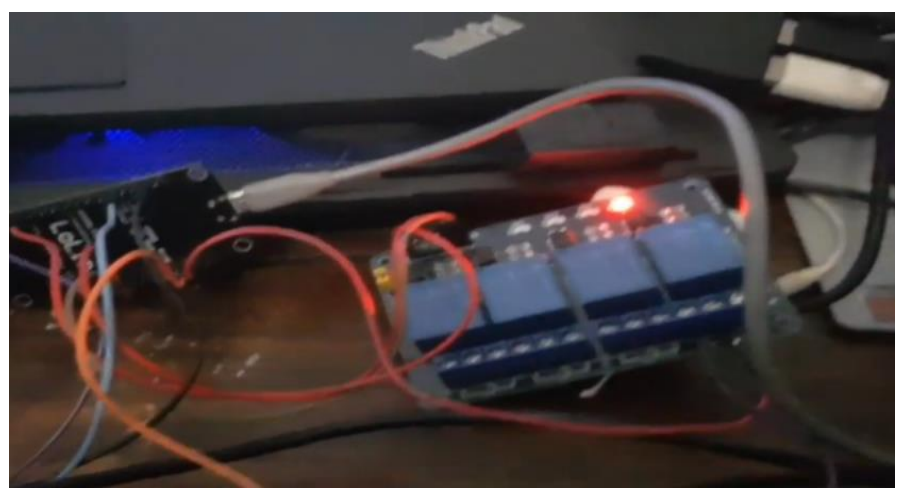

Gambar 4. Nodemcu dengan Relay

Sensor $D S 18 b 20$ merupakan sensor yang difungsikan untuk membaca cairan panas, dengan memanfaatkan tegangan kerja 3.3 VDC dari nodemcu sensor ini akan membaca suhu air kolam.

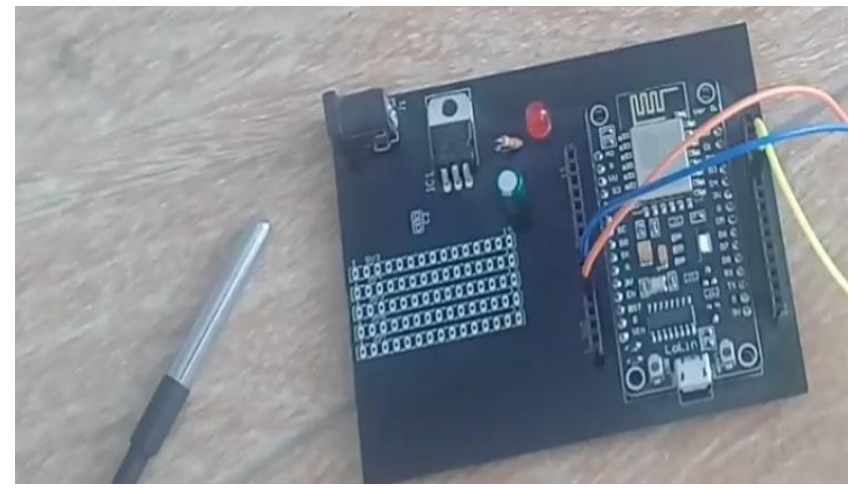

Gambar 5. Pengujian Pembacaan Nodemcu dan Ds18b20

Untuk hasil rancangan alat keseluruhan dapat dilihat pada tabel 1. dibawah menjelaskan tentang tegangan kerja yang digunakan pada rancangan alat 3.3 VDC dengan suhu kerja di kisaran, $28^{\circ} \mathrm{C}-30^{\circ} \mathrm{C}$. Sedangkan untuk posisi heater akan mati jika suhu dinilai rata rata. Sedangkan jika suhu kurang dari 28, maka Relay akan mati dan mematikan heater (Pemanas).

Tabel 1. Hasil Pengujian Monitoring Jarak Jauh dengan Internet of Things

\begin{tabular}{|c|c|c|c|c|c|}
\hline No & Suhu & Tegangan & Posisi relay & Heater & Keterangan \\
\hline 1 & $28^{\circ} \mathrm{C}-30^{\circ} \mathrm{C}$ & $3.3 \mathrm{VDC}$ & $\begin{array}{c}\text { Normal } \\
\text { close }\end{array}$ & Aktif & Terhubung ke system \\
\hline 2 & $<28^{0} \mathrm{C}$ & $3.3 \mathrm{VDC}$ & $\begin{array}{c}\text { Normal } \\
\text { close }\end{array}$ & Aktif & Terhubung ke system \\
\hline 3 & $>30^{\circ} \mathrm{C}$ & $3.3 \mathrm{VDC}$ & $\begin{array}{c}\text { Normal } \\
\text { open }\end{array}$ & Mati & Terhubung ke system \\
\hline
\end{tabular}


Vol. 1 No. 1, Feb 2021, hlm. 1 -8

DOI: https://doi.org/10.33330/.v1i1.1004

Available online at https://jurnal.stmikroyal.ac.id/index.php/jutsi

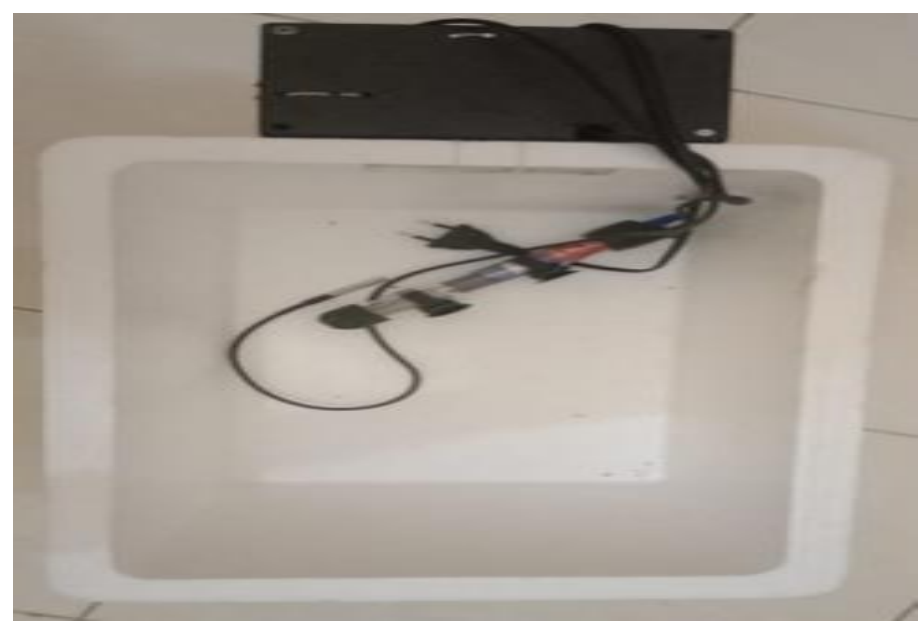

Gambar 6. Hasil Rancangan Alat Keseluruhan

Hasil dari pengaplikasian dari rancangan alat ini pemilik kolam ikan jenis ikan nila Bangkok, dan system kendali seluruh rancangan alat akan menggunakan perintah dari android dan menggunakan kendali jarak jauh.Sistem monitoring jarak jauh yang dirancang ika terjadi perubahaan suhu pada kolam ikan, maka pemilik kolam ikan menerima data perubahan suhu tersebut dan menyalakan pemanas atau mematikan pemanas secara otomatis. Sistem monitoring bisa dilihat dari thermometer suhu yang ada dihandphone pemilik kolam ikan, dan data perubahan jika melebihi ketentuan akan dikirimkan melalui notifikasi sehingga jika terjadi perubahan suhu pada kolam ikan, maka notifikasi akan dikirimkan oleh servernodemcu ke handphone pemilik android serta nilai sudu yang dibaca oleh sensorDS18b20 akan ditampilkan oleh android.

\section{SIMPULAN}

Berdasarkan analisa perancangan alat dan pembahasan, maka peneliti dapat mengambil kesimpulan sebagai berikut : Rancangan alat pembaca suhu air kolam ikan membaca suhu dari sensords $18 b 20$ yang system penyampaian datanya dikirimkan melalui internetofthings (IOT), Suhu yang efektif untuk digunakan pada air kolam ikan, nilai berada diindicator $28^{\circ} \mathrm{Csampai} 30^{\circ} \mathrm{C}$, sehingga jika dibawah indicator tersebut heater akan menyala, dan jika diatas indicator tersebut heater akan mati, Heaterakan memanaskan air kolam ikan, sehingga meminimalisir bibit ikan mati pada malam hari.

\section{DAFTAR PUSTAKA}

[1] A. Djunaedi, R. Pribadi, R. Hartati, S. Redjeki, R. W. Astuti, and B. Septiarani, "Pertumbuhan ikan Nila Larasati (Oreochromis niloticus) di Tambak dengan Pemberian Ransum Pakan dan Padat Penebaran yang Berbeda," J. Kelaut. Trop., vol. 19, no. 2, pp. 131-142, 2016.

[2] R. Muzawi, Y. Efendi, and W. Agustin, "Sistem Pengendalian Lampu Berbasis Web dan Mobile," Sains dan Teknol. Inf., vol. 4, no. 1, pp. 29-35, 2018. 
Vol. 1 No. 1, Feb 2021, hlm. 1 - 8

DOI: https://doi.org/10.33330/.v1i1.1004

Available online at https://jurnal.stmikroyal.ac.id/index.php/jutsi

[3] Y. Efendi, "Internet Of Things (Iot) Sistem Pengendalian Lampu Menggunakan Raspberry Pi Berbasis Mobile," J. Ilm. Ilmu Komput. Fak. Ilmu Komput. Univ. Al Asyariah Mandar, vol. 4, no. 2, pp. 21-27, 2018.

[4] B. Effendi, A. P. Lubis, and F. Taufik, "ANALISA LISTRIK GRATIS DARI LIMBAH ELEKTRONIKA,” J. Manaj. Inform. dan Tek. Komput., vol. 3, no. 2, pp. 72-75, 2018.

[5] H. Saputra, J. Eska, A. P. Lubis, and N. Manurung, "Design a Drink Making Tool Automatic Milk Coffee Based Arduino R3," in Journal of Physics: Conference Series, 2019, vol. 1339, no. 1, p. 12041.

[6] H. Fitriyah and G. E. Setyawan, "Sistem Pemantauan Menggunakan Blynk dan Pengendalian Penyiraman Tanaman Jamur Dengan Metode Logika Fuzzy," J. Pengemb. Teknol. Inf. dan Ilmu Komput, vol. 3, no. 4, pp. 3258-3265, 2019. 